\title{
No man is an Island: The silent struggle of invisible caregivers
}

\author{
Vibeke Lohne*, Tore Kr. Schjølberg, Lillemor Lindwall and Dagfinn Nåden \\ Oslo and Akershus University, College of Applied Sciences, Norway
}

\section{Introduction}

No man is an island, according to John Donne [1]. Illness and suffering are like rings in the water. When patients struggle, their family and network are deeply involved as well [2]. "The purpose of nursing is to assist an individual, family or community to prevent or cope with the experience of illness and suffering and, if necessary, to find meaning in these experiences" [3]. This study focuses on family caregivers'daily experiences when caring for their close ones (children, sisters and spouses) with multiple sclerosis. Patients suffering from multiple sclerosis (MS) suffer from a severe chronic and aggressive neurological disease, which involves increasing paralysis and sight problems, in addition to other problems depending on which area of the brain that is affected [4]. MS is stealing the energy and causes severe fatigue [5]. In addition, the increasing "foreignness" of the patients bodies [5] caused despair, frustration, helplessness, and desperation among both the patient and the family members [6].

Family caregivers are not a homogenous group, but rather heterogeneous and often perceived as the hidden patient [7]. Several studies uncover that family caregivers (usually close relatives) struggle alone, merely existing while trying to create a life for their family and the patient [8-11]. From their close position to the patient, the family caregivers not only assist and care; they also suffer and grieve on behalf of their loved ones as well as on behalf of themselves. Experiences of shame and guilt are common, simultaneously with feelings of isolation and being "tied up". Still, the family caregivers are a silent group, trying to survive the chaos of the situation [7].

A main focus in nursing theories has historically been holism, meaning that nurses focus on the totality of patients' situations [12]. Further, the concept of holism means that the whole is greater than the sum of the parts. There is a strong commitment to the notion that no sphere nor dimension of the individual can be understood isolated only, nor take precedence over another [13]. Nursing researchers have historically addressed scientific approaches and empirical methods to study holistic phenomena, which also include the patients' community, environment and caregivers [3,14]. Why did the nurses forget the relatives? However, the concept of environment is emerging as a scientifically significant one [15].

Due to the implementation of Health Care Coordination Reform (HCCR) in Norway, the care of patients is moving from hospitals back to their homes. Therefore the numbers of family caregivers expected to ongoing responsibility for family members will increase in the future [8]. Most family caregivers take care of family members with complex and chronic diseases and with little or no prior training [8].

\section{Background}

Multiple sclerosis challenges roles and needs as it creates a frail balance in relationships [5]. The most common courses are either acute periods of worsening (relapses) or a more gradual progressive deterioration, or a combination of both [16]. From the perspective of the patient, bodily dysfunctions lead to uncertainty, shame and bodily alienation [17-19]. According to Lohne et al. [5], individuals struggling with multiple sclerosis experienced invisibility and loneliness. Despite this, they never gave up but fought for their rights and their dignity.

Families usually report uneasiness concerning their responsibility towards their sick ones, in addition to a daily busyness [7-9] which increases their experience of burden. Although attention towards the patients' families has gradually been increasing [15], only a few recent studies, mainly quantitative and questionnaire based on family caregivers to patients suffering from multiple sclerosis were found. Based on a study by Knight et al. [20], most distress in the caregivers were associated with degenerative neurological diseases, like mobility difficulties, sudden mood changes, upsetting situations, incontinence and pain. Partners of individuals with MS experienced unpredictability and uncertainty. Alshubali et al. [21] found that caregivers to family members suffering from MS are vulnerable and in need of specific attention. Despite this, family caregivers felt that health care personnel did not really understood their daily struggle according to Söderlund [7] and Sälström [22]. Manesh and Abedi [6] found that family caregivers suffered differently at different stages of the illness: from shock, grief, denial and anger from the moment of the MS diagnosis, to gradually being confronted with financial burdens, disruptions in social relationships and career, which resulted in tension, exhaustion, vulnerability and isolation. Spouses described their life as a prison, and missed achieving time and space for themselves. Additionally, their plans for the future had changed and their life had been strongly

Correspondence to: Vibeke Lohne, Professor at Department of Nursing and Health Promotion, Oslo and Akershus University College of Applied Sciences, PO box 3, N-0130 Oslo, Norway, E-mail: vibeke.lohne@hioa.no

Key words: MS, family caregivers, invisibility, imprisoned, silent struggle Special Issue: Controversies in Multiple Sclerosis

Dr. Jagannadha Avasarala, MD, PhD

University of South Carolina School of Medicine, USA

Published: July 30, 2016 
restricted [20]. Aronsen (1997) found that the caregivers experienced strong symptoms of fatigue, had a higher risk of depression and a lower quality of life [23].

One of the most common experiences of being a caregiver appeared to be stress and strain caused by the caregiver's feelings of shame, anger and frustration, which again resulted in lack of energy [24]. Such feelings demand extreme energy, which is just what the caregivers lack. Due to the scarcity of research within this field we decided to focus on family caregivers daily experiences in a context of persons with multiple sclerosis.

\section{Purpose of the study}

The purpose of this study was therefore to explore how the family caregivers experienced and narrated their daily life as caregivers for individuals suffering from Multiple Sclerosis.

\section{Research questions}

The research questions were:

1. How do FCs understand and experience their daily life when caring for individuals with multiple sclerosis?

2. What are the FCs daily challenges when a close family member is suffering from multiple sclerosis?

3. How do FCs narrate their own living and personal daily life experiences?

\section{Methods}

\section{Study design}

The qualitative, descriptive and explorative study has a hermeneutic design, based on Ricoeur's theory of interpretation [25]. This interpretative theory involves a hermeneutic approach that includes developing a new understanding of the whole, followed by the discovering of meaningful parts and finally of the meaning of the text as a whole. This phenomenological-hermeneutic approach was used to understand the meaning of the participants' narrated experiences.

\section{Participants}

The participants were voluntarily recruited in 2012, through the Journal of Multiple Sclerosis in Norway. In order to attract as many participants as possible, the request was published twice in the journal. Nine family caregivers wanted to join the study, mostly spouses, but also siblings and parents. Four husbands and three wives participated as well as one sister. They were all between 34 and 73 years old, while most of them were between 50 and 60 years old. One of the registered participants was not available when the data collection was about to start. The participants lived throughout Norway.

\section{Context of data collection}

The narratives were collected by individual qualitative research interviews. All researchers conducted tape-recorded interviews during autumn 2013 and spring 2014. The interview guide was open and with a focus on the caregivers own experiences of their role and life situation, as well as on their experiences and meetings with health care personnel. According to the caregivers own wishes, the data collection took place in the family caregivers' homes. The narratives were rich and the participants were highly motivated to share their stories.

\section{Data analysis}

Based on Ricoeur [25,26], the analysis and interpretation of data was performed through a hermeneutic analysis. The analysis was carried out in several steps: In the first step (the naïve reading), the researchers attempted to understand the meaning of the text. The second step involved a process of narrowing down the scope, which included types of codes and structures in the text [26] and the final step involved potential horizons of meaning (p.78). To narrate is to unfold, according to Ricoeur [27].

\section{Ethical considerations}

All participants joined the study voluntarily, based on their own desire. All personal identification was separated from the interview text and the participants were guaranteed confidentiality.

\section{Findings}

According to the participants, multiple sclerosis is a sneaking or creeping disease. Nevertheless, several of the participants had felt an uneasiness on behalf of their family member for some time. Despite this, when the diagnosis was finally made, it became as a shock. Prior to the diagnosis, everybody knew in advance about that multiple sclerosis was a devastating and exhausting disease. After the diagnosis, social networks gradually disappeared and for many the family finances were put under a strain. Waiting for help, answers and results became a new lifestyle, and plans were put on hold. They had to let their earlier life and routines go as the disease unfolded. Uncertainty, vulnerability and bitterness overwhelmed the family as the symptoms progressed and every participant feared the future. Despite our focus on the experiences of the family caregivers, they focused much of their narratives on the patient. It was as if their own life had disappeared. In many ways, they were living someone else's life and had lost their earlier role and identity.

Two themes emerged from the narrated text:

A silent struggle (I) and, Imprisoned and invisible (II).

\section{A silent struggle}

The silence was experienced as total: in many ways, the patient gradually developed cognitive impairment, which left the caregiver totally alone. A 56 year old woman and experienced family caregiver narrated her life of caring responsibilities for her sick mother, her demented father, her husband when he suffered a stroke, her sister with multiple sclerosis and brain tumor as well as her daughter with multiple sclerosis. Her main experience was being invisible in the healthcare system:

"You are very vulnerable... and it provokes me when they withdraw treatments and you are left to face a splintering of responsibility. And they never ask... and they never see you.... h have tried everything ... and I have become angry and vulnerable. I have lost my confidence. And finally, I was so stressed. We change..." (3), she ascertained, while she continued: "And one of the worst things is that I have nobody to talk with. This was very hard for me.... and I got very tired. As a family caregiver I feel like being a clamp on someone's foot and never (being viewed) as a resource or as support" "(3).

A 73-year-old husband described his life as a family caregiver and spouse in this way:

"I was terribly tired, sometimes you need patience in a can... and you know, I never got breaks from my job. I was never sick. She was the 
one that was sick..... And I felt very lonely. Our general practitioner (GP) said bluntly that he knew very little about MS...I wish that the nurses could have helped me more" (4).

Another husband, that had been a family caregiver for 14 years, shared stories from his life:

"My life is very busy and there is a lot of pressure" (5),"but we just have to just get on with it and make the best out of it... in periods it is very busy, so we just have to stop and breath a little... But sometimes then a quarrel builds up to a volcanic eruption....”.

Almost without protesting, he played the second violin in the family (5).

As a vicious circle, the constantly busyness lead to physical pain: "Sometimes my shoulders hurt so much that I cannot move my arms" (6), according to a husband who fell in love with a woman with multiple sclerosis. Still, he never regretted his marriage, which was built on compassion: "We applied for help and we were told we could get one hour every month. We did not bother..." Simultaneously, his daily life was more or less filled with his sick wife.

"The diagnosis hit us like a thunderbolt...and I suddenly realized that I had to be the strong one, I had to be the tough one... we had a four month old son..." (2), according to a 32 year old wife, with a new house and no disability insurance. And she continued: "It was tough to think about the future", after her husband was diagnosed. Despite that this wife had a chronic disease herself, she found that the hardest part of her life was to ask for help. Instead, she lived her struggle alone, never feeling that she did enough.

Another wife experienced that her husband ended up in a wheelchair just six months after his diagnosis. She had taken care of him for 12 years when the specialist in charge informed her that, her husbands' MS was very aggressive. They were told that there was nothing to do, and her husband immediately adapted to this. When he gave up, she was left all alone in the daily struggle:

"Then my struggle with the health care system started", she explained: "He was depressed because the health care system had told him that he was given up... so now I had to take over the family.... my first battle was to try to get the inhibitor drugs to see if that could help ... and then we started the fight for getting assistive technology - and nobody answered and applications disappeared, and when we finally got the equipment, it was wrong...or too late. I was constantly angry and had suicidal thoughts. Finally I got help from a psychologist, and I told her that I am not crazy I just need a little hope during the roughest time in my life (8).

Several of the participants lacked assistance from health care personnel: "They were supposed to help us, but they were really working against us...which made me even more tired and frustrated. ...It is so hard to ask for help all the time," according to a 60 year old struggling wife (1).

A middle-aged wife had spiritual perspectives on her life: "This is not about how you live your life, but how you handle it," (7) she narrated. Her challenges had taught her that "illness bring new and important perspectives". Her only son had been seriously ill, in addition to her husband suffering from MS. Nevertheless, she was grateful for her life and she trusted in God: "We never get more than we can handle, (7) she repeated several times during the interview. So she managed to find meaning and trust in her daily struggle.

\section{Imprisoned and invisible (II)}

"Why us?" $(2,3,7)$, was the first reaction among the caregivers, when they received the terrifying diagnosis. Then a totally new life gradually emerged. "I was mostly alone because I had to forget my own life when I cared for her," narrated a bitter husband (4). Another vulnerable wife felt trapped in irritation and anger: "I have to be careful about what I am saying... because he gets so irritated" (1).

Another middle-aged husband became restless because of the new limitations: "Our life has physical limitations with this disease, one must always pay attention, we can never run around or go here and there..... which makes me more and more restless" (5). Unexpectedly their life had changed and the caregivers felt trapped by invisible boundaries. This invisible prison gave them a feeling of being outside society: "I had to stop working and everything. I had to stay home all the time. And I got so angry at her, sometimes" (4), which made him filled with guilt and anger. A wife of about 60 confirmed that she and her disabled husband lived a rich life together, although she also suffered from a serious disease. "We are so privileged", she said, and continued: "this is our life, and I accept it. But it is still surprising how few from our network who dare to ask how we are doing (7)". People recede. "They never ask" (7), which may contribute to a feeling of invisibility.

Despite living as an invisible prisoner the family caregivers, mostly spouses, gave more or less up their own lives to care for their partner. One husband was a man of few words, and had showed his love through actions. They had nevertheless shared a good marriage and a great love, according to his wife:

"A turning point was when I stopped expecting help from health care personnel. So I started to play very lowly and put away all my anger.... According to my experience, the health care system is not there to help sick people, but to diagnose the patient and offer treatments.... lost my husband and cared for a multi-handicapped child. But one of the worst things is that there are different people from the health care system all the time.... During some periods I had to help him twelve times a night, and still I am fighting for that my husband can stay at home. Sometimes I feel that I live in a cage. And I have to accept that I am not the master in my own house anymore... Our home has become a nursing home" (8).

As the aggressive illness increased, this brave woman and wife still fought for her husband to stay at home. The price she paid was becoming a stranger in her own home. There was a constant flow of different health care personnel in and out of her home, leaving her invisible, unfamiliar and homeless and without a role to play in her own home.

"When the health care system doesn't have sufficient treatment for a patient, they make you feel that you are only sand in the gears. And you have to take them as they are. You must never believe that they exist for you (8)"....

Based on this, this strong wife changed her strategy towards the health care personnel and became more humble, which resulted in her experiences of invisibility. Despite all of her suffering, she summed her life up at the end of the interview:

"My life is good now. The most important thing is to respect yourself and be proud of what you do, this is what is most important to me" (8).

As the disease progressed, she gave herself a promise:

"I tell myself that I am a person that keeps my marriage promises. And if I should have desires that are incompatible with taking care of 
my husband I put those desires away. Because I do not want to be a person that fails him... (and she continued) We have lots and lots of good help.... and God is good... When I have free time, I go to church. After all, our life is still meaningful" (8).

This courageous and strong wife never gave up her personal hopes and dreams, despite a life of loneliness and invisibility together with her husband, who was severely affected by MS.

\section{Discussion}

\section{Methods}

Methodologically, this study was based on qualitative individual research interviews with family caregivers. Although only eight caregivers participated, they were highly motivated to share their stories. They volunteered to participate in the study through an advertisement in a health magazine. Invisibility and silence were central themes discovered through the analysis. This no doubt contributed to the participants' motivation to participate in the study as well as their appreciation of being able to share their own stories. Four researchers performed the interviews and used the same guide with a few open questions.

\section{Findings}

Findings in this study were based on narratives from caregivers to patients suffering from multiple sclerosis in Norway. Two main themes emerged from the interpretations of the text: a silent struggle (I) and imprisoned and invisible (II). According to previous research, this study do confirms findings from the doctoral thesis of Søderlund [7], Manesh and Abedi [6], Alshubali et al. [21], Knight et al. [20], Buhse [23], as well as Vialtiano et al. [24], which increases the validity in this current study.

Invisibility in this study depends on the eyes of the observer. Being invisible may be experienced as being overlooked or rejected, instead of being understood or even being met as a fellow human. Caregivers in this study experienced not being seen or heard, neither from their family network, nor from health care personnel. This increased their silent struggle. Over time, invisibility may lead to a feeling of loss of identity, which again may be reinforced when the caregivers' own life is filled with the life of the patient. According to Lohne et al. [5], individuals suffering from MS also suffer from invisibility and loneliness. This study reveals the serious possibility that the whole family may suffer from isolation, but in separate and different ways. Additionally, as the patient felt trapped in a gradually useless body, the caregivers experienced being trapped and alone at home. Both parties in this drama are apparently sharing the same burden, but from different perspectives and for different reasons.

According to the Söderlund's thesis [7], the burden of caregivers' of patients with dementia (which has several similarities to MS), was experienced as being a stranger and an outsider in a no man's land, and longing for togetherness, harmony and vitality. Instead, they felt they were given up, living their life on the outside, experiencing a daily chaos and a loss of identity. This life was understood as an alienation [7]. Additionally, the suffering caregivers (mainly spouses) in this study were haunted by anger and guilt, which increased their vulnerability. However, they still kept their self-respect. Despite losing their network when they needed it most, they stayed and adapted to their daily struggle for their loved one. The caregivers even committed themselves to their obligations, and found meaning in the invisible daily struggle. Love and duty kept the family together. Despite their lonesome life, or perhaps because of it, several shared a strong relationship with God.

It seems, according to our research findings, that the purpose of nursing in assisting the individual and family, according to Travelbee [3], seems to having been lost in central parts of clinical nursing. According to Benner and Wrubel [14], assisting caregivers uncovers a range of meanings inherent in caring, elucidating cultural values and the significance of professional caregiving. Originally, nursing was comprehended as an interpersonal relationship, for the purpose of assisting individuals and their family to endure the suffering, and to find meaning in these experiences. This responsibility was understood as the nature of nursing [3]. Due to the intervention of Health Care Coordination Reform, the care of patients is moving from hospitals and back to their homes. This gradual yet major upheaval will increase the demands for professional assistance and care in the near future. And this call will primarily concern professional nurses.

\section{Conclusive understanding}

Narratives from the caregivers testified to a silent struggle together with experiences of being imprisoned and invisible. In many ways, they lived someone else's life, and because of this, they had lost their earlier role and identity. Interestingly enough, the whole family was suffering from isolation, but in separate and different ways. The carereceivers felt trapped in a body that gradually became useless, and caregivers experienced being trapped at home. Nevertheless, they stayed and adapted to their daily struggle for their loved ones, as the caregivers committed themselves to their obligations. Additionally, they found meaning in their invisible daily struggle. No man is an island; nevertheless, the caregivers lived a lonely life in a no-man's land. According to our findings, it seems that nurses have to rediscover their original but lost mission, which is assisting and taking better care of family caregivers:

"No man is an island, entire of itself, any man's death diminishes me, because I am involved in mankind" (J. Donne, 1642) [1].

\section{Implications for further research}

Findings call for further research, especially intervention studies, to implement reasonable actions to prevent the suffering of the caregivers and to increase trials of regular aid and assistance for the care receivers.

\section{Implications for clinical nursing}

Our task as nurses is to help the caregivers find and facilitate their own solutions to their emotional and physical suffering, based on individual and family assessments.

\section{Acknowledgements}

The authors wish to thank the participants for their generous contribution to this study, Håkon Sundane for transcribing the interviews, and Suzanne Bancel for reviewing the English. The Department of Health, Institute of Nursing at Oslo and Akershus University College of Applied Sciences, supported this study.

\section{References}

1. Donne J (1624) Devotions upon Emergent Occasions and Several Steps in my Sickness
- Meditation XVII.
2. Yalom ID (2008) “Å tittepåsolen” (Staring at the sun). ArnebergForlag (269 s).
3. Travelbee J (1971) Interpersonal Aspects of Nursing. F.A. Davis Company, (2ndedn), 240.
4. Stokes M (2004) Physical management in neurological rehabilitation. Elsevier Mosby.
5. Lohne V, Aasgaard T, Caspari S, Slettebø A, Nåden D (2010) The lonely battle for 
dignity: individuals struggling with multiple sclerosis. Nurs Ethics 17: 301-311. [Crossref]

6. Manesh AF, Abedi HA (2015) Bulletin of Environment, pharmacology and Life Sciences.4: $137-141$

7. Söderlund M (2004) Somdrabbadav en orkan (As if strucked by a hurricane). Dissertation, ÅboAkademi (The Academi of ÅBO) ÅboAkademi University Press 193.

8. Lohne V, Miaskowski C, Rustøen T (2012) The relationship between hope and caregiver strain in family caregivers of patients with advanced cancer. Cancer Nurs 35: 99-105.[Crossref]

9. Lohne V, Schjølberg TK, Lindwall L, Nåden D (2015) Pårørendetil MS pasienter helter ogstatister? (Family Caregivers to patients suffering from MS - heroes and stage extras?) MS-bladet No. 1, MS-Forbundet. Popular Science10-13.

10. Lohne V (2015) "Som sand imaskineriet" (Like sand in the gears») Guest writer in Tidsskriftfor den Norske Legeforeningen. The Journal of the Norwegian Medical Association 18: 135.

11. Lohne V (2016) Kampen for håpet (The struggle for hope). Vigmostad\&Bjørke232.

12. Chinn PL, Kramer KK (2011) Integrated Theory and Knowledge Development in Nursing.Elsevier Mosby 243.

13. Chinn PC, Jacobs MK (1987) Theory and Nurisng. The C.V. Mosby Company, Torronto, 200.

14. Benner P, Wrubel J (1989) The Primacy of Caring. Stress and Coping in Health and Illness. Adison-Welsley Publ. Company. Inc. 414.

15. Wright LM, Leahey M (2009) Nurses and Families. A guide to Family Assessment and Intervention (5thedn), F.A. Davis Company, 344.

16. Smedal T (2010) The Influence of Physiotherapy and Climate on Functioning in
Multiple Sclerosis. Aspects of physical performance, fatigue and health-related quality of life. Dissertation for the degree of philosophiae doctor (PhD), University of Bergen, Norway, 150

17. Koutsouraki E, Michmizos D (2014) Living with multiple sclerosis. MultScler 20: 133 134.[Crossref]

18. Toombs K (1985) The lived experience of disability. Human Studies 18: 9-23.

19. Finlay L (2003) The intertwining of body, self and world: A phenomenological study of living with recently diagnosed multiple sclerosis. Journal of Phenomenological Psychology34: 157-178.

20. Knight RG, Devereux RC, Godfrey HP (1997) Psychosocial consequences of caring for a spouse with multiple sclerosis. J ClinExpNeuropsychol 19: 7-19.[Crossref]

21. Alshubaili AF, Ohaeri JU, Awadalla AW, Mabrouk AA (2008) Family caregiver quality of life in multiple sclerosis among Kuwaitis: a controlled study. BMC Health Serv Res 8: 206.[Crossref]

22. Sällström C (1994) Spouses experiences of living with a partner with Alzheimer's disease. Dissertattion. Umeå University Medical Dissertations, Umeå.

23. Buhse M (2008) Assessment of caregiver burden in families of persons with multiple sclerosis. J NeurosciNurs 40: 25-31.[Crossref]

24. Vitaliano P, Young H, Zhang J (2004)Is caregiving a risk factor for illness. Current Directions in Psychological Science 13: 1

25. Ricoeur P (1981) Hermeneutics \& the Human Sciences. (eds. Transl. John B. Thompson). Cambridge University Press, Paris 313.

26. Ricoeur P (1976) Interpretation Theory. Discourse and the Surplus of Meaning. Texas Christian University Press, USA 107.

27. Ricoeur P (1950) The Mystery of Being. Volume I:Reflection and Mystery. St Augustine's Press, Indiana, 2001, 219.

Copyright: @2016 Lohne V. This is an open-access article distributed under the terms of the Creative Commons Attribution License, which permits unrestricted use, distribution, and reproduction in any medium, provided the original author and source are credited. 